\title{
Proton Magnetic Resonance Spectroscopic Evidence of Glial Effects of Cumulative Lead Exposure in the Adult Human Hippocampus
}

\section{Citation}

Weisskopf, Marc G., Howard Hu, David Sparrow, Robert E. Lenkinski, and Robert O. Wright. 2007. Proton Magnetic Resonance Spectroscopic Evidence of Glial Effects of Cumulative Lead Exposure in the Adult Human Hippocampus. Environmental Health Perspectives 115(4): 519-523.

\section{Published Version}

doi:10.1289/ehp.9645

\section{Permanent link}

http://nrs.harvard.edu/urn-3:HUL.InstRepos:4889574

\section{Terms of Use}

This article was downloaded from Harvard University's DASH repository, and is made available under the terms and conditions applicable to Other Posted Material, as set forth at http:// nrs.harvard.edu/urn-3:HUL.InstRepos:dash.current.terms-of-use\#LAA

\section{Share Your Story}

The Harvard community has made this article openly available.

Please share how this access benefits you. Submit a story.

\section{Accessibility}




\title{
Proton Magnetic Resonance Spectroscopic Evidence of Glial Effects of Cumulative Lead Exposure in the Adult Human Hippocampus
}

\author{
Marc G. Weisskopf, ${ }^{1}$ Howard Hu, ${ }^{1,2}$ David Sparrow, ${ }^{2,3,4}$ Robert E. Lenkinski, ${ }^{5}$ and Robert O. Wright ${ }^{1,2}$
}

${ }^{1}$ Department of Environmental Health, Harvard School of Public Health, Boston, Massachusetts, USA; ${ }^{2}$ The Channing Laboratory, Department of Medicine, Brigham and Women's Hospital, and Harvard Medical School, Boston, Massachusetts, USA; ${ }^{3} \mathrm{VA}$ Boston Healthcare System, Boston, Massachusetts, USA; ${ }^{4}$ Boston University School of Medicine, Boston, Massachusetts, USA; ${ }^{5}$ Department of Radiology, Beth Israel Deaconess Medical Center, Boston, Massachusetts, USA

BACKGROUND: Exposure to lead is known to have adverse effects on cognition in several different populations. Little is known about the underlying structural and functional correlates of such exposure in humans.

ОвјестіVEs: We assessed the association between cumulative exposure to lead and levels of different brain metabolite ratios in vivo using magnetic resonance spectroscopy (MRS).

METHODS: We performed MRS on 15 men selected from the lowest quintile of patella bone lead within the Department of Veterans Affairs' Normative Aging Study (NAS) and 16 from the highest to assess in the hippocampal levels of the metabolites $N$-acetylaspartate, myoinositol, and choline, each expressed as a ratio with creatine. Bone lead concentrations-indicators of cumulative lead exposure-were previously measured using K-X-ray fluorescence spectroscopy. MRS was performed on the men from 2002 to 2004.

RESULTS: A $20-\mu \mathrm{g} / \mathrm{g}$ bone and $15-\mu \mathrm{g} / \mathrm{g}$ bone higher patella and tibia bone lead concentration-the respective interquartile ranges within the whole NAS-were associated with a 0.04 [ $95 \%$ confidence interval (CI), 0.00-0.08; $p=0.04]$ and $0.04(95 \% \mathrm{CI}, 0.00-0.08 ; p=0.07)$ higher myoinositol-to-creatine ratio in the hippocampus. After accounting for patella bone lead declines over time, analyses adjusted for age showed that the effect of a $20-\mu \mathrm{g} / \mathrm{g}$ bone higher patella bone lead level doubled $(0.09 ; 95 \% \mathrm{CI}, 0.01-0.17 ; p=0.03)$.

Conclusions: Cumulative lead exposure is associated with an increase in the myinositol-to-creatine ratio. These data suggest that, as assessed with MRS, glial effects may be more sensitive than neuronal effects as an indicator of cumulative exposure to lead in adults.

KEY WORDS: bone lead, choline, glia, hippocampus, myoinositol, $N$-acetylaspartate, neuronal viability, proton MRS. Environ Health Perspect 115:519-523 (2007). doi:10.1289/ehp.9645 available via http://dx.doi.org/ [Online 3 January 2007]

Adverse effects of elevated blood and bone lead levels on cognitive function have been examined in various populations including children (Banks et al. 1997; Canfield et al. 2003; Needleman and Gatsonis 1990; Schwartz 1994), occupationally exposed adults (BalbusKornfeld et al. 1995; Bleecker et al. 1997; Fiedler et al. 2003; Schwartz and Stewart 2000; Stewart et al. 1999), and nonoccupationally exposed adults (Muldoon et al. 1996; Payton et al. 1998; Weisskopf et al. 2004b; Wright et al. 2003). These effects have been assessed using primarily behavioral and neuropsychologic evaluations and are some of the most consistently reported impairments associated with lead exposure. Regarding the molecular and cellular effects of lead exposure that may underlie the behavioral effects, there is a good deal of data from experimental studies in animals, but relatively little is known about the structural and functional correlates of leadrelated brain dysfunction in humans. A better understanding of the underlying pathology would not only have potential benefits for prevention and treatment of the adverse effects but could also help identify those effects specifically attributable to lead.

Magnetic resonance spectroscopy (MRS) provides a noninvasive method with which to monitor biochemical aspects of acute and chronic stages of neurologic disease in the human brain (Ross et al. 2006). The development of spatially localized spectroscopic methods that sample the relative levels of metabolites from volumes of tissue defined from magnetic resonance imaging (MRI) scans has provided a basis for integrating the biochemical information obtained by MRS with the anatomical and pathological information obtained from MRI. MRS has been used as a method for assessing both neuronal viability and demyelination. The use of MRS in neurologic disease has grown rapidly over the past decade, but the use of MRS in the setting of environmental insult to the brain is quite new. Earlier MRS studies of leadexposed individuals do suggest effects on brain metabolites, but these studies focused on small numbers of very highly exposed children (Meng et al. 2005; Trope et al. 1998, 2001). Examination of the effects of exposure levels to which a much larger population would be exposed have not been done. We assessed the association between cumulative exposure to lead-as measured with K-X-ray fluorescence (KXRF) of bone lead-and brain metabolite ratios measured with MRS among participants in the Department of
Veterans Affairs' (VA) Normative Aging Study (NAS), a community-based cohort of elderly U.S. men with lead exposure similar to a similarly aged cross-section of the general U.S. population.

\section{Methods}

Study population. This research was conducted on a subgroup of the VA NAS, a multidisciplinary longitudinal study of aging in men established by the VA in 1963 (Bell et al. 1966). The research herein was approved by the Human Subjects Committees of the Boston VA Medical Center, the Brigham and Women's Hospital, and the Harvard School of Public Health. This cohort has been described in detail elsewhere (Hu et al. 1996). Briefly, healthy men from the general population in the greater Boston, Massachusetts, area were recruited in the 1960s. These men reported for medical examinations every 3-5 years, at which time they underwent clinical examinations and completed extensive health and lifestyle related questionnaires. The attrition rate for all causes has been $<1 \%$ annually and the response rate to mailed questionnaires that supplement onsite examinations has been $>80 \%$.

Address correspondence to M.G. Weisskopf, Harvard School of Public Health, Occupational Health Program, Landmark Center, 401 Park Dr., PO Box 15697, Boston MA 02215 USA. Telephone: (617) 384-8872. Fax: (617) 384-8994. E-mail: mweissko@hsph.harvard.edu

This research was supported by grants from the National Institutes of Health (NIH) (R01 ES005257), the National Center for Research Resources, General Clinical Research Center (M01RR02635), Small Business Innovation Research (2R44 ES03918-02, K23-ES000381), National Institute of Environmental Sciences (NIEHS) Center (ES00002). M.G.W was supported by NIEHS grant K01-ES012653. Additional data from the VA Normative Aging Study were collected with support from the Research Services and the Cooperative Studies Program/Epidemiology Research and Information Center of the U.S. Department of Veterans Affairs, the Massachusetts Veterans Epidemiology Research and Information Center (MAVERIC), the NIH (grants R01-AA08941, R01-AG13006, R01-AG14345, R01-AG18436), and the U.S. Department of Agriculture, Agricultural Research Service (contract 53-K06-510).

The views expressed in this article are those of the authors and do not necessarily represent the views of the U.S. Department of Veterans Affairs.

The authors declare they have no competing financial interests.

Received 23 August 2006; accepted 3 January 2007. 
Beginning in 1991 those who gave their informed consent presented to the Ambulatory Clinical Research Center of the Brigham and Women's Hospital for a KXRF measurement of lead content in the tibia and patella bones. We selected 105 men from the lowest quintile of patella bone lead and 119 from the highest quintile to participate in the MRS study. Of these, 13 from the lowest and 12 from the highest quintiles were either too sick or ineligible for MRS because of possible metal in their body or we were unable to contact them $(n=$ 27 from the lowest and 41 from the highest quintile). Of the remaining 65 men from the lowest and 66 from the highest quintile, 15 (23.1\%) and $16(24.2 \%)$, respectively, agreed to undergo an MRS scan. These scans were performed from 2002 through 2004. Bone lead for these 31 participants was measured between 1994 and 1999.

Bone lead levels measured by KXRF. Bone lead was measured at two anatomical sitesthe midtibial shaft and the patella-with an ABIOMED KXRF instrument (ABIOMED, Danvers, MA) as described previously ( $\mathrm{Hu}$ et al. 1998). The tibia and patella have been targeted for bone lead research because these two bones are primarily cortical and trabecular bone, respectively, with different ramifications in terms of toxicity (Hu et al. 1998). A 30-min measurement was taken at the midshaft of the left tibia and at the left patella, after each region had been washed with a $50 \%$ solution of isopropyl alcohol. The tibial midshaft was taken as the midpoint between the tibial plateau and the medial malleolus. The KXRF beam collimator was sited perpendicular to the flat bony surface of the tibia and at $30^{\circ}$ in the lateral direction for the patella.

Magnetic resonance spectroscopy. MRI and ${ }^{1} \mathrm{H}$-MRS were performed on a $3 \mathrm{~T}$ scanner (Signa LX; General Electric, Waukesha, WI). Anatomical MR images were obtained in the coronal plane using a 3D magnetization-prepared rapid gradient echo (MPRAGE) sequence developed in-house. The sequence was acquired with a field of view of $24 \mathrm{~cm}$,
32 slices with a $3-\mathrm{mm}$ slice thickness, $256 \times$ 256 matrix size 600-msec inversion time, repetition time (TR) of $8 \mathrm{msec}$, echo time (TE) of $3 \mathrm{msec}$, a bandwidth of $32 \mathrm{kHz}$, and 1 excitation. These images were used to select graphically the left and right hippocampus for solvent suppressed ${ }^{1} \mathrm{H}$-MRS. Single-voxel ${ }^{1} \mathrm{H}$-MRS of the hippocampus was performed using point-resolved spectroscopy (PRESS). The ${ }^{1} \mathrm{H}$ spectra $\left(2 \times 2 \times 2 \mathrm{~cm}^{3}\right)$ were acquired with a repetition time of $2 \mathrm{sec}$, time to echo of $35 \mathrm{msec}$, spectral width of $5,000 \mathrm{~Hz}, 2,048$ time points, and 128 averages $(4.3 \mathrm{~min}$ ) and an eight-step phase cycling scheme. Crusher gradients of $32 \mathrm{mT} / \mathrm{m}$ amplitude (80\% of the full-scale system gradient amplitude) and a duration of $4 \mathrm{msec}$ (maximum crusher width) were equally spaced around the $180^{\circ}$ pulses with 10 -msec spacing. Spatial saturation pulses were applied at the edge of the PRESS voxel to minimize contamination of signal from outside the prescribed voxel. Linear shims were used to correct the B0 inhomogeneity across the investigated voxel. Spectral analysis was performed using LC-Model (Stephen Provencher Inc., Oakville, Ontario, $\mathrm{CN}$ ) embedded in the Spectroscopy Analysis by GE package (SAGE) (GE Medical Systems, Milwaukee, WI). After any upgrade to the scanner we validated MRS results on phantoms. The output of LC-Model gave both the metabolite ratios (expressed as relative concentration taking into account the number of protons in each compound) and their standard deviations. Peak assignments for the different metabolites were those routinely used (Kreis et al. 1997).

Data analysis. Analysis was performed on the main metabolites detected by MRS, that is, $N$-acetylaspartate (NAA), myoinositol $(\mathrm{mI})$, and choline (Cho), all expressed as a ratio with creatine $(\mathrm{Cr})$, which is generally stable in the brain and normalizes the relative intensities. When modeling the overall association between bone lead biomarkers and metabolite ratios, we included measurements of metabolite ratios from the hippocampus on

Table 1. Characteristics by participation status and patella lead level.

\begin{tabular}{|c|c|c|c|c|}
\hline \multirow[b]{2}{*}{ Characteristic } & \multicolumn{2}{|c|}{$\begin{array}{l}\text { Did not participate } \\
\text { Patella lead level }\end{array}$} & \multicolumn{2}{|c|}{$\begin{array}{c}\text { Participated } \\
\text { Patella lead level }\end{array}$} \\
\hline & $\operatorname{Low}(n=90)$ & $\operatorname{High}(n=103)$ & $\operatorname{Low}(n=15)$ & $\operatorname{High}(n=16)$ \\
\hline Mean age in years \pm SD at $\mathrm{MRS}^{a}$ & $73.0 \pm 6.2$ & $78.0 \pm 5.9$ & $73.2 \pm 4.7$ & $80.7 \pm 6.1$ \\
\hline Mean years \pm SD of education & $15.3 \pm 2.5$ & $13.2 \pm 2.6$ & $16.3 \pm 3.1$ & $13.4 \pm 2.6$ \\
\hline Mean \pm SD serum creatinine (mg/dL) & $1.1 \pm 0.5$ & $1.1 \pm 0.3$ & $1.0 \pm 0.2$ & $1.2 \pm 0.4$ \\
\hline Mean \pm SD systolic blood pressure $(\mathrm{mmHg})$ & $134 \pm 16$ & $134 \pm 17$ & $133 \pm 15$ & $135 \pm 20$ \\
\hline Diabetes, $n(\%)$ & $7(8)$ & $5(5)$ & 0 & $1(6)$ \\
\hline Hypertension, $n(\%)$ & $28(31)$ & $36(35)$ & $4(27)$ & $7(44)$ \\
\hline Taking hypertension medication, $n(\%)$ & $9(10)$ & $15(15)$ & $1(7)$ & $6(38)$ \\
\hline Myocardial infarction, $n(\%)$ & 0 & $6(6)$ & 0 & $1(6)$ \\
\hline Stroke, $n(\%)$ & 0 & $3(3)$ & 0 & $1(6)$ \\
\hline Median (IOR) patella lead ( $\mu \mathrm{g} / \mathrm{g}$ bone) & $10(6-14)$ & $48(44-60)$ & $9(5-15)$ & $63(43-86)$ \\
\hline Median (IOR) tibia lead ( $\mu \mathrm{g} / \mathrm{g}$ bone) & $11(7-17)$ & $32(24-41)$ & $13(9-17)$ & $41(38-59)$ \\
\hline
\end{tabular}

$\mathrm{Hg}$, mercury.

${ }^{a}$ Age on 1 January 2002 for those without MRS. both sides of the brain of each participant in our analyses by using repeated measures, with a compound symmetry covariance structure, to account for the within subject correlation. The MRS scans were performed an average of $6.0(\mathrm{SD}=1.2)$ years after the KXRF measurements; therefore, we report on additional analyses after adjusting each subject's patella bone lead levels for the years between the bone measurement and the MRS scan based on a first-order exponential decay function with a half-life of 8 years as determined previously among NAS participants (Kim et al. 1997). We did not adjust tibia concentrations because the same previous study found that they did not change over time periods similar to those described here. Other data on subjects were taken from their most recent regular NAS visit. Interquartile ranges (IQR) are the values of a given distribution at the 25th and 75 th percentiles.

\section{Results}

Demographic and health characteristics of NAS men selected for participation in this study are shown in Table 1 according to whether they participated and whether they were in the low- or high-patella lead group. When segregated by patella lead levels, there was little difference between those men that did and did not participate. None of the men who participated had been diagnosed with Alzheimer disease. In the complete NAS cohort we have previously reported inverse associations between bone lead and cognitive function (Weisskopf et al. 2004b, 2007; Wright et al. 2003), and in the small subset that participated in this MRS study, the MiniMental State Examination (Folstein et al. 1975) scores were higher among the low-lead group (mean, 26.9; $\mathrm{SD}=2.0$ ) than among the high-lead group (mean, 26.3; SD = 1.8). A representative scan showing the voxel of interest in the left hippocampus along with the proton spectra is shown in Figure 1. Among NAS men in the low-lead group the mean \pm $\mathrm{SD} \mathrm{mI} / \mathrm{Cr}, \mathrm{NAA} / \mathrm{Cr}$, and $\mathrm{Cho} / \mathrm{Cr}$ ratios were $0.89 \pm 0.29,1.26 \pm 0.38$, and $0.33 \pm 0.09$, respectively. Among men in the high-lead group, the mean \pm SD ratios were $0.99 \pm 0.25$, $1.24 \pm 0.31$ ), and $0.41 \pm 0.29)$.

In univariate analyses, both patella and tibia bone lead were associated with a perturbation of the $\mathrm{mI} / \mathrm{Cr}$ ratio (Table 2). Among men in the NAS with bone lead-from whom the 31 in this study were selected-the interquartile range of patella and tibia lead concentration is approximately 20 and $15 \mu \mathrm{g} / \mathrm{g}$ bone, respectively (Weisskopf et al. 2007). A 20- $\mu \mathrm{g} / \mathrm{g}$ bone higher patella lead concentration and $15-\mu \mathrm{g} / \mathrm{g}$ bone higher tibia lead concentration were associated with an increase in $\mathrm{mI} / \mathrm{Cr}$ ratio of 0.04 [95\% confidence interval $(\mathrm{CI}), 0.00-0.08 ; p=$ 0.03 ] and 0.04 (95\% CI, 0.00-0.08; $p=0.06$ ), 
respectively. Each of these effects represents approximately $14 \%$ of the SD of the distribution of $\mathrm{mI} / \mathrm{Cr}$ in the hippocampus among this group. $\mathrm{mI}$ is an important component of the phosphatidylinositol second messenger system, and lithium treatment has been reported to influence the brain levels of this metabolite (Silverstone et al. 2005). None of the subjects in our study used lithium.

When we adjusted for age in the models, the effect sizes for both patella $(0.05$ per $20 \mu \mathrm{g} / \mathrm{g})$ and tibia $(0.05$ per $15 \mu \mathrm{g} / \mathrm{g})$ became stronger than in the crude analyses, but the precision was slightly reduced because of the high correlation between age and bone lead. None of the other metabolite ratios showed significant associations with either patella or tibia lead (Table 2). In analyses adjusted for age and using patella lead levels adjusted to account for decline in patella lead levels over the time between bone lead measurement and MRS, the results were also stronger than those in the main analyses: the effect estimate for a $20-\mu \mathrm{g} / \mathrm{g}$ bone patella lead increase was almost double $(0.09 ; 95 \%$ CI, $0.00-0.18 ; p=$ $0.04)$ that in the age-adjusted main analysis. Figure 2 shows the individual $\mathrm{mI} / \mathrm{Cr}$ ratios adjusted to 75 years of age indicating this association with patella lead.

Renal insufficiency can affect lead burden and possibly $\mathrm{mI}$ levels. Therefore, we also ran analyses after excluding the two men with serum creatinine $>1.5 \mathrm{mg} / \mathrm{dL}$ (one of whom was the participant who reported both a previous myocardial infarction and stroke) and a third man with diabetes, all three of whom were in the high-lead group. In these analyses the age-adjusted association between patella lead adjusted to account for decline in lead over time, and $\mathrm{mI} / \mathrm{Cr}$ was even stronger than in the main analyses (effect estimate per $20 \mu \mathrm{g} / \mathrm{g}$ bone: $0.11 ; 95 \% \mathrm{CI}, 0.02-0.19 ; p=$ 0.02 ). In addition, we ran analyses adjusting for hypertension (or use of hypertension medication) because these were reported more frequently in the high-lead group. In these analyses the age-adjusted association between patella lead adjusted to account for decline in lead over time and $\mathrm{mI} / \mathrm{Cr}$ was also stronger than the main analyses (effect estimate per $20 \mu \mathrm{g} / \mathrm{g}$ bone: 0.13 ; $95 \% \mathrm{CI}, 0.05-0.21 ; p=$ $0.002)$. Associations with other metabolite ratios remained nonsignificant in all of these additional analyses.
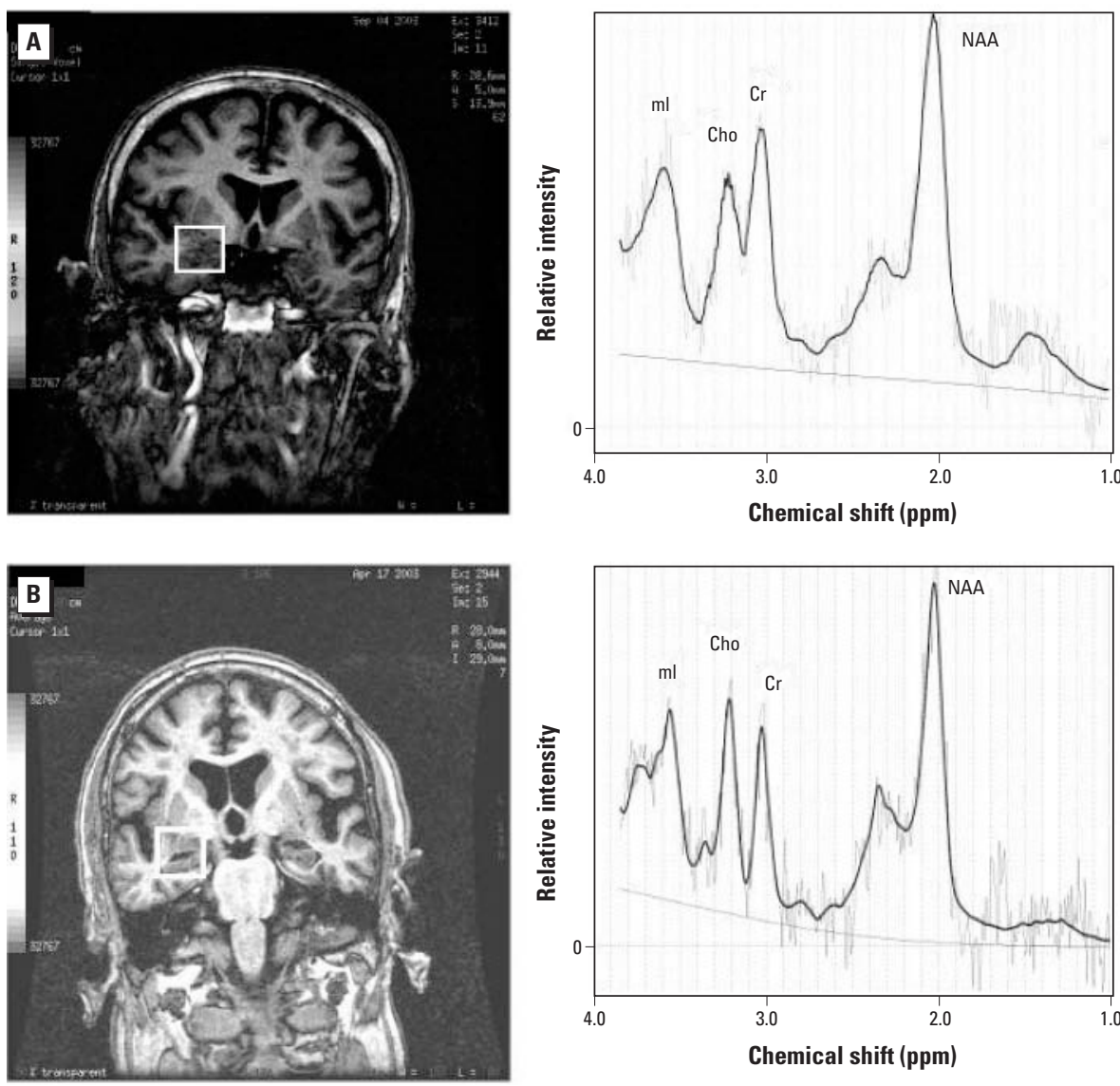

Figure 1. Example MRI and magnetic resonance spectroscopy spectra from participants in the low $(A)$ and high $(B)$ bone lead groups. The left panels show the region of interest outlined by a thick white box overlying the right hippocampal region on the MRIs. The right panels show the accompanying spectra with peaks for $\mathrm{ml}$, Cho, $\mathrm{Cr}$, and NAA indicated.

\section{Discussion}

In this analysis of elderly men with lifetime exposures to lead similar to those of the general U.S. population of similar age, we found an association between an indicator of higher cumulative lead exposure-measured by lead concentration in bone-and increased $\mathrm{mI} / \mathrm{Cr}$ ratios in the hippocampal region. There were no significant associations with any of the other metabolite ratios. Results were more pronounced when analyses were adjusted for age, although less precise because of high correlation between age and bone lead. However, when adjusting for age in analyses of patella lead adjusted for the time between the KXRF and MRS, the association with $\mathrm{mI} / \mathrm{Cr}$ was both stronger and more precise. The magnitude of the increase in $\mathrm{mI} / \mathrm{Cr}$ for an interquartile range higher bone lead concentration was about $14 \%$ of the SD of $\mathrm{mI} / \mathrm{Cr}$ in this group.

This study is, to our knowledge, the first to examine the association of cumulative exposure to lead in a group of adults and metabolic changes in brain as measured with MRS. It is important to note that the exposure to lead in our subjects is not occupational but rather from the general environment and thus at levels that a much larger population of elderly adults worldwide would be expected to have. The few previous studies of lead exposure and MRS have focused on children. A study in China of 6 children with blood lead $>27 \mu \mathrm{g} / \mathrm{dL}$ and 6 children with blood lead $<10 \mu \mathrm{g} / \mathrm{dL}$ found lower NAA/Cr ratios in both the frontal cortex and hippocampus associated with the higher lead exposure (Meng et al. 2005). mI levels were not determined. A study in the United States of 16 children with blood lead levels between 23 and $65 \mu \mathrm{g} / \mathrm{dL}$ and 5 children with blood lead $<10 \mu \mathrm{g} / \mathrm{dL}$ also found reduced NAA/Cr, but no change in $\mathrm{mI} / \mathrm{Cr}$, in the frontal cortex associated with the higher lead exposure (Trope et al. 2001), which is similar to their previous report of two cousins with disparate lead exposure (Trope et al. 1998). In all these studies the exposures were high. The average blood lead concentration of children

Table 2. Crude effect estimates ${ }^{a}$ for tibia and patella lead on MRS metabolite ratios in the hippocampus.

\begin{tabular}{|c|c|c|c|}
\hline Metabolite & $\begin{array}{c}\text { Effect } \\
\text { estimate }\end{array}$ & $95 \% \mathrm{Cl}$ & $p$-Value \\
\hline \multicolumn{4}{|l|}{ Patella lead } \\
\hline $\mathrm{ml} / \mathrm{Cr}$ & 0.04 & 0.00 to 0.08 & 0.03 \\
\hline $\mathrm{NAA} / \mathrm{Cr}$ & 0.00 & -0.05 to 0.05 & 0.99 \\
\hline Cho/Cr & -0.01 & -0.04 to 0.02 & 0.42 \\
\hline \multicolumn{4}{|l|}{ Tibia lead } \\
\hline $\mathrm{ml} / \mathrm{Cr}$ & 0.04 & 0.00 to 0.08 & 0.06 \\
\hline $\mathrm{NAA} / \mathrm{Cr}$ & 0.00 & -0.05 to 0.06 & 0.90 \\
\hline $\mathrm{Cho} / \mathrm{Cr}$ & -0.01 & -0.04 to 0.03 & 0.66 \\
\hline
\end{tabular}

${ }^{a}$ Effect estimates were per 20 and $15 \mu \mathrm{g} / \mathrm{g}$ increases in patella and tibia lead concentration, respectively, which are the interquartile ranges for those measures in the parent Normative Aging Study population from which the subjects in this study were selected. Because of missing metabolite values the number of subjects in analyses of $\mathrm{ml} / \mathrm{Cr}$ is 29 . 
12-19 years of age in the United States was $5.6 \mu \mathrm{g} / \mathrm{dL}$ in 2001-2002 (National Center for Environmental Health 2005). Differences from our current findings could be related to the age or exposure level differences from these previous studies. The only study in adults examined monozygotic twin brothers with markedly different lead levels - both blood and bonealthough they were dramatically elevated in both twins as a result of occupational exposure (Weisskopf et al. 2004a). The NAA/Cr ratio in the hippocampus was found to be lower in the twin with the higher lead levels. $\mathrm{mI}$ levels were not determined. A principal difference in the present study is that the exposures were chronic and low level. Thus, the fact that changes in $\mathrm{mI} / \mathrm{Cr}$ but not in NAA/Cr were detected could suggest that $\mathrm{mI} / \mathrm{Cr}$ is a more sensitive indicator than other metabolite ratios of chronic lowlevel lead exposure in adults.

In the cortex, NAA is located in neuronal cell bodies, and a decrease in NAA is generally accepted as an indicator of neuronal damage and loss (Ross et al. 2006). In contrast, $\mathrm{mI}$ is found primarily in glial cells. Inositol polyphosphates are important neuronal signaling molecules, but their concentrations in the brain relative to $\mathrm{mI}$ itself are quite small and they do not contribute to the MRS peak assigned to $\mathrm{mI}$, which is composed mostly of $\mathrm{mI}$ alone and mI-monophosphate (Ross 1991). Although the pathological significance of elevated $\mathrm{mI}$ is not completely clear, it has been proposed to reflect increased numbers of glial cells (Brand et al. 1993; Ross et al. 2006). Elevated $\mathrm{mI}$ and decreased NAA have been widely reported in patients with Alzheimer disease compared with normal controls in neocortical, limbic cortical, and hippocampal regions (Ross et al. 2006). Although other dementias share the feature of a decrease in $\mathrm{NAA} / \mathrm{Cr}$, the increase in $\mathrm{mI} / \mathrm{Cr}$ is a relatively

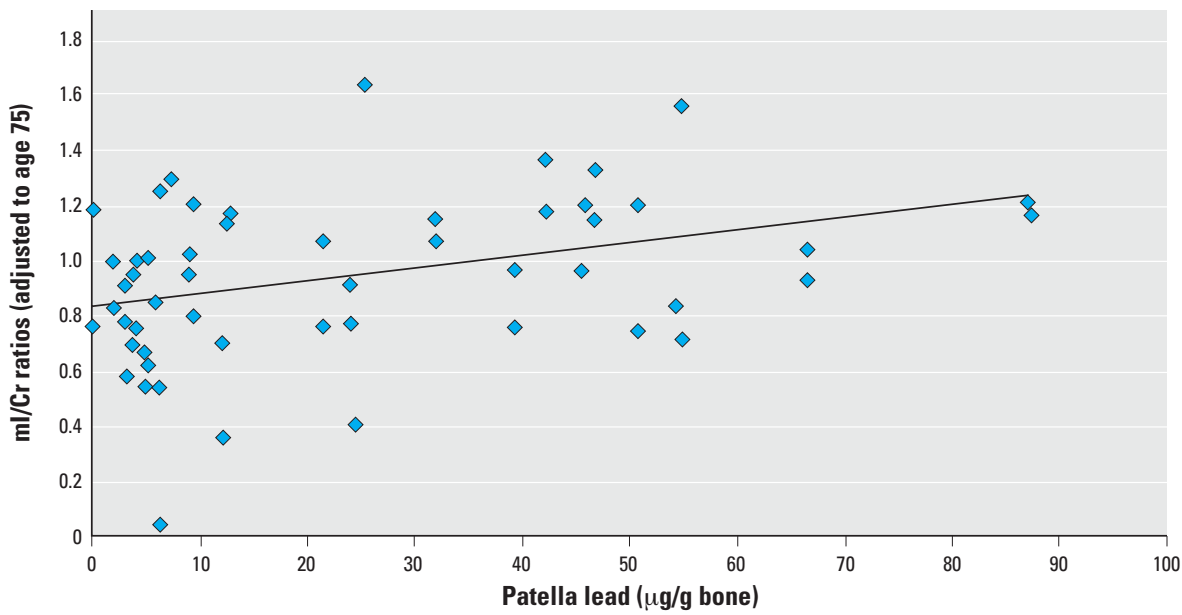

Figure 2. $\mathrm{ml} / \mathrm{Cr}$ ratio (adjusted to 75 years of age) in the hippocampus by patella bone lead level (solid line is linear trend). Patella bone lead levels are adjusted to account for decay between time of bone lead measurement and MRS scan. $\mathrm{ml} / \mathrm{Cr}$ ratios from the hippocampus on each side of the brain of participants are shown. $p$ for trend $=0.04$. distinctive aspect of Alzheimer disease and has been suggested as indicative of gliosis (Kantarci et al. 2004; Ross et al. 2006). It has been proposed that the initial MRS changes in the pathologic progression of Alzheimer disease is an increase in $\mathrm{mI} / \mathrm{Cr}$ and that a decrease in NAA/Cr develops later in the disease course, based on data from the posterior cingulate gyrus (Kantarci et al. 2000). This is supported by data indicating that glial proliferation and plaque formation occur in preclinical Alzheimer disease (Mackenzie et al. 1995; Morris and Price 2001), whereas neuronal loss may not occur at this stage (West et al. 2004). The difference in $\mathrm{mI} / \mathrm{Cr}$ reported between Alzheimer disease patients and normal controls (Kantarci et al. 2004; Ross et al. 2006) is similar in magnitude to the change we found associated with an interquartile range higher patella bone lead concentration.

Little is known about the structural and functional correlates of lead-related brain dysfunction in humans. Largely from in vitro and animal work it is known that lead accumulation in the brain after exposure is preferentially in glia rather than in neurons (Lindahl et al. 1999; Tiffany-Castiglioni et al. 1989), and chronic lead exposure in rats has been found to induce astrogliosis in the hippocampus and cerebellum (Selvin-Testa et al. 1994). The astroglial response to lead exposure may in fact be an initial attempt to protect neurons from injury (Struzynska et al. 2005). Our results are consistent with these animal studies. Although lead most certainly adversely affects neurons as well, it may be that, compared with effects on glial cells, higher levels of lead exposure are needed before those effects can be detected as a reduced NAA/Cr ratio in humans with MRS, and, therefore, the glial effects may be an earlier MRS marker of effects of chronic lead exposure.
A limitation to this study is the small sample size for study of the effects of relatively low levels of lead exposure. Nonetheless, this is the largest such study to date. Further study of a larger cohort would provide better power to detect possible other associations. Although the participation rate was low, those that participated and those that did not appeared similar in many respects. An additional concern is that participants in the high-lead group were somewhat older than those in the lowlead group. However, the $\mathrm{mI} / \mathrm{Cr}$ ratio appears to decrease with normal aging (Ross et al. 2006); thus our finding is in the opposite direction of the possible age bias. Indeed, our results were stronger when adjusted for age. Another concern is that renal insufficiency can affect lead burden and may influence $\mathrm{mI}$ levels. However, our results were stronger when the two men with serum creatinine $>1.5 \mathrm{mg} / \mathrm{dL}$ and one man with diabetes were excluded from analyses. Last, the region of interest analyzed, while centering on the hippocampus, includes some surrounding tissue. Therefore, to the extent that the effects of lead on metabolite ratios differ within and immediately outside the hippocampus, observed associations would be weakened.

In summary, we find an association between increased cumulative lead exposure and increased $\mathrm{mI} / \mathrm{Cr}$ ratios in the hippocampus among a group with general population levels of lead exposure. We did not see significant associations between lead and any of the other metabolite ratios. These data suggest that in humans, as has been seen in animal studies, glial effects may also be the first or most sensitive indicators of adverse effects of cumulative lead exposure in adults, and these changes are similar to what is seen in early stages of Alzheimer disease.

\section{REFERENCES}

Balbus-Kornfeld JM, Stewart W, Bolla KI, Schwartz BS. 1995. Cumulative exposure to inorganic lead and neurobehavioural test performance in adults: an epidemiological review. Occup Environ Med 52(1):2-12.

Banks EC, Ferretti LE, Shucard DW. 1997. Effects of low level lead exposure on cognitive function in children: a review of behavioral, neuropsychological and biological evidence. Neurotoxicology 18(1):237-281.

Bell B, Rose CL, Damon A. 1966. The Veterans Administration Iongitudinal study of healthy aging. Gerontologist 6(4):179-184.

Bleecker ML, Lindgren KN, Ford DP. 1997. Differential contribution of current and cumulative indices of lead dose to neuropsychological performance by age. Neurology 48(3):639-645.

Brand A, Richter-Landsberg C, Leibfritz D. 1993. Multinuclear NMR studies on the energy metabolism of glial and neuronal cells. Dev Neurosci 15(3-5):289-298.

Canfield RL, Henderson CR Jr, Cory-Slechta DA, Cox C, Jusko TA, Lanphear BP. 2003. Intellectual impairment in children with blood lead concentrations below 10 microg per deciliter. N Engl J Med 348(16):1517-1526.

Fiedler N, Weisel C, Lynch R, Kelly-McNeil K, Wedeen R, Jones $K$, et al. 2003. Cognitive effects of chronic exposure to lead and solvents. Am J Ind Med 44(4):413-423.

Folstein MF, Folstein SE, McHugh PR. 1975. “Mini-Mental State". A practical method for grading the cognitive state of patients for the clinician. J Psychiatr Res 12(3):189-198. 
Hu H, Aro A, Payton M, Korrick S, Sparrow D, Weiss ST, et al. 1996. The relationship of bone and blood lead to hypertension. The Normative Aging Study. JAMA 275(15):1171-1176.

Hu H, Rabinowitz M, Smith D. 1998. Bone lead as a biologica marker in epidemiologic studies of chronic toxicity: conceptual paradigms. Environ Health Perspect 106:1-8.

Kantarci K, Jack CR, Jr., Xu YC, Campeau NG, O'Brien PC Smith $\mathrm{GE}$, et al. 2000. Regional metabolic patterns in mild cognitive impairment and Alzheimer's disease: A 1H MRS study. Neurology 55(2):210-217.

Kantarci K, Petersen RC, Boeve BF, Knopman DS, Tang-Wa DF, O'Brien PC, et al. 2004. 1H MR spectroscopy in common dementias. Neurology 63(8):1393-1398.

Kim R, Landrigan C, Mossmann P, Sparrow D, Hu H. 1997. Age and secular trends in bone lead levels in middle-aged and elderly men: three-year longitudinal follow-up in the Normative Aging Study. Am J Epidemiol 146(7):586-591.

Kreis R, Koster M, Kamber M, Hoppeler H, Boesch C. 1997. Peak assignment in localized ${ }^{1} \mathrm{H}$ MR spectra of human muscle based on oral creatine supplementation. Magn Reson Med 37(2):159-163.

Lindahl LS, Bird L, Legare ME, Mikeska G, Bratton GR, TiffanyCastiglioni E. 1999. Differential ability of astroglia and neuronal cells to accumulate lead: dependence on cell type and on degree of differentiation. Toxicol Sci 50(2):236-243.

Mackenzie IR, Hao C, Munoz DG. 1995. Role of microglia in senile plaque formation. Neurobiol Aging 16(5):797-804.

Meng XM, Zhu DM, Ruan DY, She JQ, Luo L. 2005. Effects of chronic lead exposure on ${ }^{1} \mathrm{H}$ MRS of hippocampus and frontal lobes in children. Neurology 64(9):1644-1647.

Morris JC, Price AL. 2001. Pathologic correlates of nondemented aging, mild cognitive impairment, and earlystage Alzheimer's disease. J Mol Neurosci 17(2):101-118.

Muldoon SB, Cauley JA, Kuller LH, Morrow L, Needleman HL, Scott J, et al. 1996. Effects of blood lead levels on cognitive function of older women. Neuroepidemiology 15(2):62-72.

National Center for Environmental Health. 2005. Third National Report on Human Exposure to Environmental Chemicals NCEH Pub. No. 05-0570. Atlanta, GA:Centers for Disease Control and Prevention.

Needleman HL, Gatsonis CA. 1990. Low-level lead exposure and the $\mathrm{IQ}$ of children. A meta-analysis of modern studies. JAMA 263(5):673-678.

Payton M, Riggs KM, Spiro A, 3rd, Weiss ST, Hu H. 1998 Relations of bone and blood lead to cognitive function: the VA Normative Aging Study. Neurotoxicol Teratol 20(1):19-27.

Ross BD. 1991. Biochemical considerations in ${ }^{1} \mathrm{H}$ spectroscopy. Glutamate and glutamine; myo-inositol and related metabolites. NMR Biomed 4(2):59-63.

Ross BD, Coletti P, Lin A. 2006. Magnetic resonance spectroscopy of the brain: neurospectroscopy. In: Clinical Magnetic Resonance Imaging (Edelman RR, Hesselink JR, Zlatkin MB, Crues JV, eds). Philadelphia:Saunders Elsevier, 1840-1907.

Schwartz BS, Stewart WF. 2000. Different associations of blood lead, meso 2,3-dimercaptosuccinic acid (DMSA)-chelatable lead, and tibial lead levels with blood pressure in 543 former organolead manufacturing workers. Arch Environ Health 55(2):85-92.

Schwartz J. 1994. Low-level lead exposure and children's IQ: a meta-analysis and search for a threshold. Environ Res 65(1): 42-55.

Selvin-Testa A, Loidl CF, Lopez-Costa JJ, Lopez EM, PecciSaavedra J. 1994. Chronic lead exposure induces astrogliosis in hippocampus and cerebellum. Neurotoxicology 15(2):389-401.

Silverstone PH, McGrath BM, Kim H. 2005. Bipolar disorder and myo-inositol: a review of the magnetic resonance spectroscopy findings. Bipolar Disord 7(1):1-10.

Stewart WF, Schwartz BS, Simon D, Bolla KI, Todd AC, Links J.
1999. Neurobehavioral function and tibial and chelatable lead levels in 543 former organolead workers. Neurology 52(8):1610-1617.

Struzynska L, Chalimoniuk M, Sulkowski G. 2005. The role of astroglia in $\mathrm{Pb}$-exposed adult rat brain with respect to glutamate toxicity. Toxicology 212(2-3):185-194.

Tiffany-Castiglioni E, Sierra EM, Wu JN, Rowles TK. 1989. Lead toxicity in neuroglia. Neurotoxicology 10(3):417-443.

Trope I, Lopez-Villegas D, Cecil KM, Lenkinski RE. 2001. Exposure to lead appears to selectively alter metabolism of cortical gray matter. Pediatrics 107(6):1437-1442.

Trope I, Lopez-Villegas D, Lenkinski RE. 1998. Magnetic resonance imaging and spectroscopy of regional brain structure in a 10-year-old boy with elevated blood lead levels. Pediatrics 101(6):1066-1067.

Weisskopf MG, Hu H, Mulkern RV, White R, Aro A, Oliveira S, et al. 2004a. Cognitive deficits and magnetic resonance spectroscopy in adult monozygotic twins with lead poisoning. Environ Health Perspect 112:620-625.

Weisskopf MG, Proctor SP, Wright R0, Schwartz J, Spiro A, Sparrow D, et al. 2007. Prospective study of cumulative lead exposure and performance in different cognitive domains among elderly men: the VA Normative Aging Study. Epidemiology 18(1):59-66.

Weisskopf MG, Wright RO, Schwartz J, Spiro A, Sparrow D, Aro $A$, et al. 2004b. Cumulative lead exposure and prospective change in cognition among elderly men: the VA Normative Aging Study. Am J Epidemiol 160(12):1184-1193.

West MJ, Kawas CH, Stewart WF, Rudow GL, Troncoso JC. 2004. Hippocampal neurons in pre-clinical Alzheimer's disease. Neurobiol Aging 25(9):1205-1212.

Wright RO, Tsaih SW, Schwartz J, Spiro A III, McDonald K, Weiss ST, et al. 2003. Lead exposure biomarkers and minimental status exam scores in older men. Epidemiology 14(6):713-718. 